\title{
Persistent Pain after Spinal Cord Injury Is Maintained by Primary Afferent Activity
}

\author{
Qing Yang, Zizhen Wu, Julia K. Hadden, Max A. Odem, Yan Zuo, Robyn J. Crook, Jeffrey A. Frost, and Edgar T. Walters \\ Department of Integrative Biology and Pharmacology, University of Texas Medical School at Houston, Texas, 77030
}

Chronic pain caused by insults to the CNS (central neuropathic pain) is widely assumed to be maintained exclusively by central mechanisms. However, chronic hyperexcitablility occurs in primary nociceptors after spinal cord injury (SCI), suggesting that SCI pain also depends upon continuing activity of peripheral sensory neurons. The present study in rats (Rattus norvegicus) found persistent upregulation after SCI of protein, but not mRNA, for a voltage-gated $\mathrm{Na}^{+}$channel, Nav1.8, that is expressed almost exclusively in primary afferent neurons. Selectively knocking down Nav1.8 after SCI suppressed spontaneous activity in dissociated dorsal root ganglion neurons, reversed hypersensitivity of hindlimb withdrawal reflexes, and reduced ongoing pain assessed by a conditioned place preference test. These results show that activity in primary afferent neurons contributes to ongoing SCI pain.

Key words: Chronic pain; dorsal root ganglion; Nav1.8; neuropathic pain; nociceptor; spinal contusion

\section{Introduction}

After peripheral injury or inflammation, central sensitization in the spinal cord promotes allodynia, hyperalgesia, and spontaneous pain, but this central sensitization often requires continuing sensory activity (Baron et al., 2013). In contrast, pain resulting from injury or inflammation within the CNS (central neuropathic pain) is usually assumed to be maintained by central alterations (Finnerup, 2013). However, recent findings suggest that persistent hyperexcitability and spontaneous activity (SA) in primary sensory neurons might promote spinal cord injury (SCI) pain. First, SA occurs in peripheral terminals (Carlton et al., 2009) and in cell bodies of nociceptors in vivo and after dissociation from dorsal root ganglia (DRG; Bedi et al., 2010) long after SCI. Second, reduction of TRPV1 function reverses behavioral hypersensitivity after SCI (Wu et al., 2013). TRPV1 is expressed most abundantly in primary nociceptors (Cavanaugh et al., 2011), suggesting that activity in primary sensory neurons might drive reflex hypersensitivity after SCI. Furthermore, the aversive quality of pain (Baastrup et al., 2010; Navratilova et al., 2013) might also be driven by primary afferent activity after SCI.

A strong test of the hypothesis that activity in primary afferent neurons helps to maintain SCI pain (Walters, 2012) is enabled by the selective expression of a voltage-gated $\mathrm{Na}^{+}$channel, Nav1.8, in somatic sensory neurons. Nav1.8 is absent in central neurons

\footnotetext{
Received Dec. 19, 2013; revised June 30, 2014; accepted July 3, 2014.

Author contributions: Q.Y., Z.W., R.J.C., J.A.F., and E.T.W. designed research; Q.Y., Z.W., J.K.H., M.A.O., Y.Z., and R.J.C. performed research; Q.Y., Z.W., M.A.O., Y.Z., R.J.C., J.A.F., and E.T.W. analyzed data; E.T.W. wrote the paper. This work was supported by grants from the United States Army Medical Research Acquisition Activity-United States Department of Defense, Mission Connect/TIRR Foundation, and the Craig H. Neilsen Foundation. We thank Carmen Dessauer, Raymond Grill, and Hongzhen Hu for helpful suggestions.

The authors declare no competing financial interests.

Correspondence should be addressed to Edgar T. Walters or Qing Yang, Department of Integrative Biology and

Pharmacology, University of Texas Medical School at Houston, 6431 Fannin Street, MSB 4116, Houston, TX, 77030.

E-mail: Edgar.T.Walters@uth.tmc.edu or Qing.Yang@uth.tmc.edu.

DOI:10.1523/JNEUROSCI.5316-13.2014

Copyright $\odot 2014$ the authors $\quad 0270-6474 / 14 / 3410765-05 \$ 15.00 / 0$
}

(Akopian et al., 1999; Shields et al., 2012) and is important for SA in primary afferent neurons after peripheral insults (Roza et al., 2003; Jarvis et al., 2007). Here, we report that knockdown of Nav1.8 channels after SCI reduces SA in primary afferent neurons, reverses reflex hypersensitivity, and ameliorates a pain-like aversive state.

\section{Materials and Methods}

Procedures. All procedures complied with guidelines of the International Association for the Study of Pain and were approved by the institutional animal care and use committee. Male rats $(200-350 \mathrm{~g})$ were maintained under a $12 \mathrm{~h}$ reversed light/dark cycle and tested during the dark phase. Additional methodological details are available (Bedi et al., 2010; Wu et al., 2013).

SCI procedures. Contusion injury occurred at vertebral segment T10 (Bedi et al., 2010). Rats were deeply anesthetized with ketamine (80 $\mathrm{mg} / \mathrm{kg})$, xylazine $(10 \mathrm{mg} / \mathrm{kg})$, and acepromazine $(0.75 \mathrm{mg} / \mathrm{kg})$ before laminectomy at T10, followed by a spinal impact using an Infinite Horizon impactor (150 kdyne, $1 \mathrm{~s}$ dwell time). Sham-operated ("sham") animals received identical procedures except for spinal impact. Animals accepted for study exhibited Basso, Beattie, and Bresnahan (BBB) hindlimb motor scores of $01 \mathrm{~d}$ after SCI (Basso et al., 1995). All showed partial locomotor recovery by the end of testing, with extensive movement of all joints in the hindlimbs (BBB score $\geq 7$ ).

Antisense oligodeoxynucleotide (ODN) knockdown of Nav1.8. Previous studies identified an antisense oligodeoxynucleotide (ASO) sequence that is taken up in vivo by DRG neurons after intrathecal delivery and reduces expression of Nav1.8 protein (Porreca et al., 1999; Lai et al., 2002). This sequence, $5^{\prime}$-TCC-TCT-GTG-CTT-GGT-TCT-GGC-CT-3', and a mismatched oligodeoxynucleotide (MMO) sequence, $5^{\prime}$-TCC-TTCGTG-CTG-TGT-TCG-TGC-CT-3', were purchased from Sigma-Aldrich. Approximately 1 month after SCI, rats were anesthetized with isoflurane and a chronic intrathecal catheter was inserted at the atlantooccipital joint terminating at the lumbar enlargement. Animals showing additional impairment after catheterization (altered body posture or forelimb function) were killed. Intrathecal injections ( $45 \mu \mathrm{g}$ of ODN in $5 \mu \mathrm{l}$ of saline, followed by a $10 \mu \mathrm{l}$ of saline flush) were given 1-2 months after injury, twice daily for $3 \mathrm{~d}$, and then once daily for $2 \mathrm{~d}$. 
Western blot analysis of Nav protein expression. At the end of ODN injection, animals were deeply anesthetized and bilateral L4 and L5 ganglia were removed and immediately homogenized in RIPA buffer (Teknova) with protease inhibitors. Lysate protein concentrations were determined by bicinchoninic acid assay (Pierce). Equal amounts of total protein $(30 \mu \mathrm{g})$ were resolved by SDS-PAGE $(4-20 \%$ Tris-HCl; BioRad) after 1:1 dilution with Laemmli buffer, transferred to a PVDF membrane, blocked with $10 \%$ nonfat dry milk, and incubated overnight at $4^{\circ} \mathrm{C}$ with antibodies against Nav1.8 (catalog \#AB9274; Millipore), Nav1.6 (catalog \#ASC-009; Alomone Labs), Nav1.7 (catalog \#ASC-008; Alomone Labs), or Nav1.9 (catalog \#AB-9222; Millipore), and $\beta$-actin (catalog \#ab6276; Abcam). Secondary HRP anti-rabbit or anti-mouse IgGs were incubated for $1 \mathrm{~h}$ at $22^{\circ} \mathrm{C}$. Blots were developed using an enhanced chemiluminescence substrate (Pierce). Optical densities were normalized to $\beta$-actin.

$R T-P C R$ analysis of Nav1.8 mRNA expression in DRG neurons and spinal cord. Total RNA was extracted from homogenized DRG or spinal cord with on-column DNase digestion (E.Z.N.A. Total RNA Kit I) and cDNA was synthesized by MMLV reverse transcriptase (Invitrogen) using random primer. Rat Nav1.8 primers were TCCCGGGGAAGGCTACATTA (forward) and TAATGTTGGCCCGGTCACTC (reverse; Hu et al., 2013); rat GAPDH primers were CCCCCAATGTATCCGTTGTG (forward) and TAGCCCAGGATGCCCTTTAGT (reverse; Piller et al., 2013). mRNA abundance was determined by real-time PCR (LightCycler 480; Roche) with SYBR Green Master Mix (Sigma). Preincubation at $95^{\circ} \mathrm{C}$ for 3 min was followed by 45 amplification cycles $\left(95^{\circ} \mathrm{C}\right.$ for $30 \mathrm{~s}$, $57^{\circ} \mathrm{C}$ for $30 \mathrm{~s}$, and $72^{\circ} \mathrm{C}$ for $30 \mathrm{~s}$ ) and fluorescence collection at $60^{\circ} \mathrm{C}$. Gene expression was normalized to Gapdh and expressed as fold change of sham control averaged over three replicates from each of three animals in each group.

Dissociation and culture of DRG neurons. Selected DRG neurons (L5, $\mathrm{L} 4, \mathrm{~T} 12, \mathrm{~T} 11, \mathrm{~T} 9, \mathrm{~T} 8)$ were minced and incubated for $40 \mathrm{~min}$ at $34^{\circ} \mathrm{C}$ with trypsin $(0.4 \mathrm{mg} / \mathrm{ml})$ and collagenase $\mathrm{D}(1.6 \mathrm{mg} / \mathrm{ml})$. DRG fragments were triturated and the neurons were plated without serum or growth factors onto dishes coated with poly-L-lysine and kept overnight in DMEM under $5 \% \mathrm{CO}_{2}, 95 \%$ humidity at $37^{\circ} \mathrm{C}$.

Recording from dissociated DRG neurons. Whole-cell patch recordings of SA were made at $\sim 23^{\circ} \mathrm{C}$ from small neurons $18-26 \mathrm{~h}$ after dissociation, as described previously (Bedi et al., 2010). Tetrodotoxin (TTX)resistant currents were measured in solution containing the following (in $\mathrm{mm}): 130 \mathrm{NaCl}, 4 \mathrm{KCl}, 2 \mathrm{CaCl}_{2}, 1 \mathrm{MgCl}_{2}, 0.1 \mathrm{CdCl}_{2}, 10$ TEA-Cl, 10 HEPES, and 5 glucose, and a pipette solution containing the following (in m) : $100 \mathrm{CsCl}, 30 \mathrm{CsF}, 8 \mathrm{NaCl}, 1 \mathrm{CaCl}_{2}, 1 \mathrm{MgCl}_{2}, 0.4 \mathrm{Na} 2 \mathrm{GTP}, 4$ MgATP, 10 EGTA, and 10 HEPES. Current-voltage relationships were determined with $250 \mathrm{~nm}$ TTX and a holding potential of $-60 \mathrm{mV}$ to isolate Nav1.8 channels (Cummins et al., 1999); $200 \mathrm{~ms}$ command potentials were delivered from -100 to $50 \mathrm{mV}$ in $10 \mathrm{mV}$ increments at $5 \mathrm{~s}$ intervals, with each command following a $100 \mathrm{~ms}$ conditioning prepulse to $-120 \mathrm{mV}$.

Reflex hypersensitivity tests. Tests were conducted by investigators blinded to treatment before injury and just before and at the end of ODN treatment (Bedi et al., 2010; Wu et al., 2013). Animals were habituated to test chambers on day 1 . On days 2 and 3 , heat and mechanical test stimuli were given for habituation to test procedures; data were collected from tests on days 4 and 5 . Hindlimb heat hypersensitivity was tested by the Hargreaves radiant heat method. Mechanical hypersensitivity was tested with calibrated von Frey filaments delivered to the glabrous surface of hindpaws.

Conditioned place preference test for ongoing pain. We modified conditioned place preference (CPP) procedures used in peripheral pain models (King et al., 2009). A commercial CPP box (Med Associates) with automated data collection had three chambers with equal levels of dim illumination: black and white end chambers and a connecting gray chamber. On day 1 ( $\sim 2$ months after injury), each rat was permitted to explore the gray and black (but not white) chambers. Conditioning trials occurred on days 2-4. Each morning, $0.5 \mathrm{ml}$ of vehicle (saline) was injected intraperitoneally $10 \mathrm{~min}$ before confinement in the black chamber for $60 \mathrm{~min}$. Three hours later, the same rat was injected with retigabine $(10 \mathrm{mg} / \mathrm{kg}$ in $0.5 \mathrm{ml}$ of saline; Yang et al., 2013) $10 \mathrm{~min}$ before confinement in the white chamber. On day 5 , each rat was placed in the gray chamber with unrestricted access to all chambers for $15 \mathrm{~min}$. Data are presented as the difference in time spent in the retigabine-paired (white) chamber minus time in the vehicle-paired (black) chamber during the drug-free day 5 test. The total number of crossings into all three chambers provided objective criteria to exclude SCI animals exhibiting excessive locomotor impairment ( $<21$ crossings; two SCI + MMO and two SCI + ASO animals) or insufficient spinal injury ( $>250$ crossings; one SCI + MMO and one SCI + ASO animal). For comparison, sham animals exhibited $190 \pm 26$ total crossings during the test.

Statistical analysis. Data are presented as means \pm SEM. Comparisons were made with Student's $t$ tests or one- or two-way ANOVA, followed by Bonferroni's post hoc tests. SA incidence was compared using Fisher's exact tests.

\section{Results}

Nav1.8 antisense treatment selectively reduces Nav1.8 expression in DRG neurons after upregulation by SCI We investigated whether SCI had any effect on Nav1.8 expression in L4 and L5 DRG. These DRG are sufficiently far from the vertebral T10 contusion site that few C-fiber neurons should be injured directly by the T10 injury (Bedi et al., 2010), but neurons in these DRG may be exposed to inflammatory signals disseminated after SCI (McKay and McLachlan, 2004; Alexander and Popovich, 2009), which might alter Nav1.8 expression (Yu et al., 2011). Processing for Western blot analysis began immediately after excision of L4 and L5 DRG 1 month after injury (Fig. 1A). The amount of Nav1.8 protein differed among DRG from naive, sham, and SCI animals $\left(F_{(2,11)}=8.83 ; p=0.005\right)$, with the levels being significantly higher in ganglia from SCI than naive or sham animals $(p<0.01$ and $p<0.05$, respectively). No difference was found between SCI and sham groups in Nav1.8 mRNA expression in lumbar DRG, nor was any evidence found for Nav1.8 mRNA expression in lumbar spinal cord in either group (Fig. 1B). Using a Nav1.8 ASO sequence (Lai et al., 2002), we compared the expression of four different Nav proteins after Nav1.8 ASO treatment to the corresponding expression after Nav1.8 MMO treatment (Fig. 1C). No significant differences were found in expression of Nav1.6, Nav1.7, or Nav1.9 channels in SCI animals after lumbar Nav1.8 ASO treatment, whereas Nav1.8 protein expression was significantly lower after Nav1.8 ASO treatment than after MMO treatment $(p=0.002)$.

\section{Nav1.8 antisense treatment reduces TTX-resistant $\mathrm{Na}^{+}$ current and spontaneous activity in DRG neurons after SCI}

Nav1.8 channels mediate a distinctive $\mathrm{Na}^{+}$current that is resistant to TTX and has an unusually depolarized voltage dependence of fast inactivation (Akopian et al., 1996; Dib-Hajj et al., 1997). We assessed the degree of reduction of Nav1.8-mediated, TTX-resistant $\mathrm{Na}^{+}$current by antisense knockdown in small DRG neurons from SCI animals. In the presence of $250 \mathrm{~nm}$ TTX, a whole-cell voltage-clamp pulse protocol that inactivates the other TTX-resistant Nav channel in DRG neurons, Nav1.9, was used (Cummins et al., 1999). Depolarizing steps from a $-60 \mathrm{mV}$ holding potential produced inward currents with relatively slow activation and inactivation kinetics (Fig. $2 \mathrm{~A}$, left), with a threshold level of $\sim-30 \mathrm{mV}$ and a peak at $\sim 0 \mathrm{mV}$ (Fig. $2 A$, middle), suggestive of an Nav1.8-mediated current. The peak amplitude of evoked current was lower in DRG neurons after in vivo Nav1.8 ASO injections (Fig. 2A, right) than after MMO injections when tested $\sim 20 \mathrm{~h}(p<0.0001$, unpaired $t$ test $)$, but not $\sim 40 \mathrm{~h}$, after the last injection, consistent with known rates of turnover of $\mathrm{Nav}$ channels (Porreca et al., 1999). 


\section{A Nav1.8 protein in DRG after SCl}

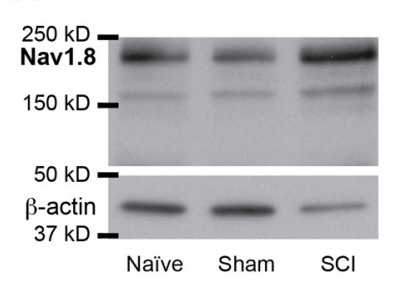

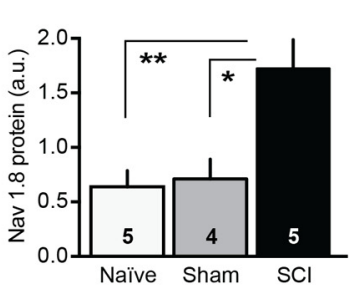

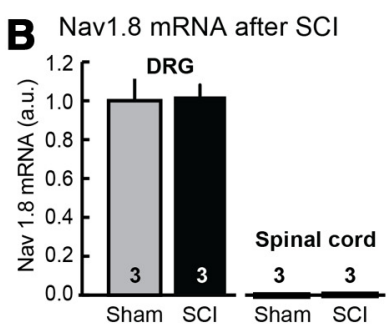

C Nav protein in DRG after Nav1.8 knockdown
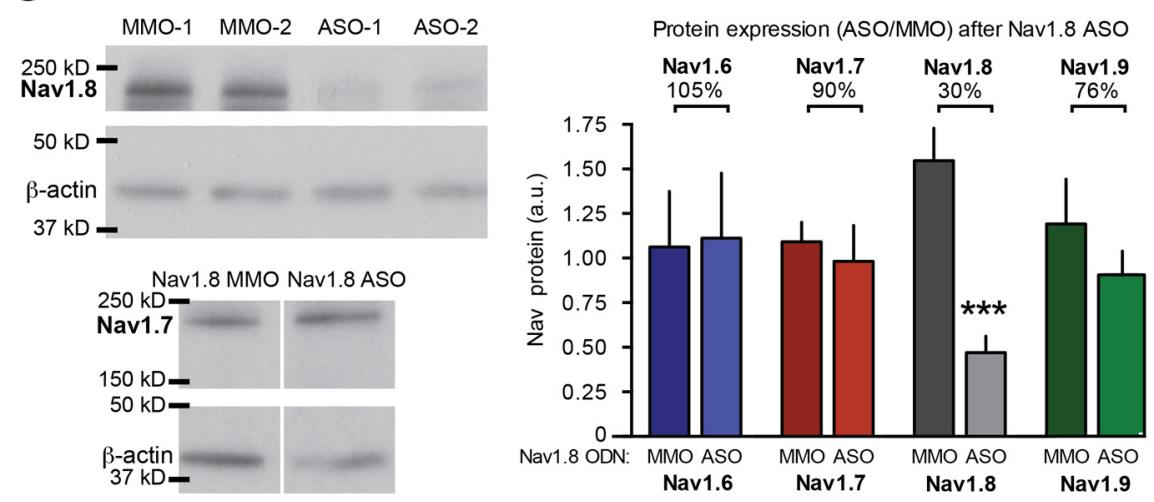

Figure 1. Effects of $\mathrm{SCl}$ and Nav1.8 antisense treatment on Nav channel expression. $\boldsymbol{A}, \mathrm{SCl}$ increases Nav1.8 protein in L4 and $\mathrm{L} 5$ DRG 1 month after injury. Left, Sample Western blots. Right, Increase in Nav1.8 protein after SCI (normalized to $\beta$-actin). Number of animals tested (four DRG per animal) is indicated in each bar. $\boldsymbol{B}$, Nav1.8 mRNA expression is detectable in DRG, but not spinal cord, and is not altered by SCl. C, Nav1.8 ASO treatment selectively knocks down Nav1.8 protein expression. Left, Sample Western blot (two animals each for Nav1.8 and one each for Nav1.7). Right, Normalized expression of four Nav channels. Percentages indicate mean relative expression for each channel protein after Nav1.8 AS0 treatment compared with Nav1.8 MM0 treatment.

$\left(F_{(1,9)}=11.03 ; p=0.009\right)$, and their interaction $\left(F_{(2,57)}=4.82 ; p=0.011\right)$. Post hoc comparison revealed higher postODN withdrawal latency in ASO-treated than in MMO-treated rats $(p=0.0019)$.

To investigate ongoing pain, we used operant conditioning of place preference to a chamber paired with retigabine injection. Retigabine opens KCNQ $\mathrm{K}^{+}$channels, reducing neuronal excitability and, in other models, behavioral hypersensitivity (Brown and Passmore, 2009). Importantly, we found recently that retigabine suppresses SA in small DRG neurons and reverses hyperreflexia after SCI (Yang et al., 2013). One day after the $3 \mathrm{~d}$ differential conditioning procedure, sham animals preferred the vehicle-paired black chamber (as do naive animals, unpublished observations), whereas SCI animals showed relative preference for the white, retigabine-paired chamber $(p=0.003$, unpaired $t$ test; Fig. $3 C$, left). Preference for the white chamber in SCI, but not sham, animals indicates that retigabine is only rewarding when an SCI-induced aversive state is present. To test whether knockdown of Nav1.8 reduces the conditioned shift in preference toward the white chamber in SCI animals, we tested animals after MMO or ASO treatment

An important prediction was that knockdown of Nav1.8 expression would reduce SCI-induced SA. SCI quadrupled the incidence of SA in small DRG neurons (Fig. $2 B$, left) dissociated from L4 and L5 ganglia $3 \mathrm{~d}$ after injury compared with neurons dissociated from naive animals ( $p<0.0001$; Fig. $2 B$, right), and this increase was abolished by Nav1.8 ASO injections at the lumbar level ( $p=0.003$ vs SCI). Similarly, SCI increased the incidence of SA 1-3 months after SCI, and this increase was abolished by lumbar SCI + ASO treatment $(p=0.006)$. SA incidence was significantly greater in lumbar DRG neurons after SCI or SCI + MMO treatment than in lumbar DRG neurons after lumbar SCI + ASO treatment $(p=0.003)$. No significant effects on SCIinduced increases in SA were found in DRG neurons dissociated from thoracic ganglia (Fig. $2 B$, right) after Nav1.8 ASO treatment at the lumbar level.

\section{Nav1.8 antisense treatment reverses hindlimb hyperreflexia and ongoing pain after SCI}

Persistent sensitization of hindlimb withdrawal responses evoked by mechanical and heat test stimuli was found 1-3 months after SCI, similar to earlier comparisons of SCI, sham, and naive groups (Bedi et al., 2010), and this sensitization was reversed by Nav1.8 ASO treatment. For mechanical sensitivity (Fig. 3A), significant effects were found for test sequence (pre-SCI, post-SCI, post-ODN; $\left.F_{(2,84)}=23.9 ; p<0.0001\right)$, ODN treatment $\left(F_{(1,57)}=\right.$ $4.5 ; p=0.039)$, and their interaction $\left(F_{(2,57)}=4.82 ; p=0.0012\right)$. Post hoc comparison revealed higher post-ODN withdrawal threshold in ASO-treated than MMO-treated rats $(p=0.0009)$. Twenty-eight of 29 animals showed mechanical hypersensitivity after SCI (before ODN treatment) and 72\% also showed heat hypersensitivity. In these animals, significant effects were found for test sequence $\left(F_{(2,57)}=14.2 ; p<0.0001\right)$, ODN treatment and found that, compared with the SCI + MMO animals, SCI + ASO animals significantly preferred the black chamber $(p=$ 0.045 ; Fig. $3 C$, right). The absence in SCI + ASO animals of a shift in preference away from the innately preferred, vehicle-paired black chamber suggests that Nav1.8 function is necessary to maintain ongoing pain after SCI.

\section{Discussion}

Finding that persistent pain induced by SCI requires Nav1.8, which is expressed almost exclusively in primary afferent neurons (Akopian et al., 1999; Shields et al., 2012), indicates that Nav1.8expressing sensory neurons play a major role in driving SCI pain and perhaps associated central neuropathic alterations (Finnerup, 2013). Our results confirm that intrathecal application of a Nav1.8 ASO sequence reduces expression of Nav1.8 protein in DRG and functional activity of Nav1.8 channels (Porreca et al., 1999; Lai et al., 2002; Gold et al., 2003; Yu et al., 2011). We also demonstrate that this knockdown is highly specific; Nav1.8 ASO treatment did not significantly reduce DRG expression of related $\mathrm{Na}^{+}$channels: Nav1.6 and Nav1. 7 (see also Porreca et al., 1999) and Nav 1.9. Reversal of reflex hypersensitivity by Nav1.8 ASO treatment has also been shown in peripheral injury and inflammation models (Yoshimura et al., 2001; Villarreal et al., 2005; Joshi et al., 2006; Morgan and Gebhart, 2008; Miao et al., 2010).

Our hypothesis that SA in primary afferent neurons drives chronic pain after SCI (Bedi et al., 2010; Walters, 2012) is supported by three findings. First, Nav1.8 mRNA was expressed in DRG, but not the spinal cord, even after SCI. Second, Nav1.8 knockdown eliminated the increase in SA in DRG neurons and hyperreflexia after SCI, suggesting that electrical activity in DRG neurons maintains hyperreflexia. This probably explains the strong correlation between the incidence of SA in dissociated 


\section{A TTX-resistant current following Nav1.8 knockdown}

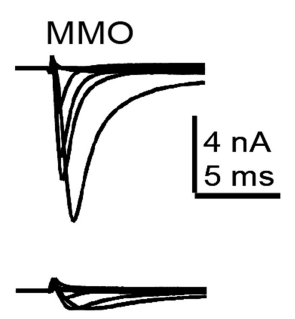

ASO

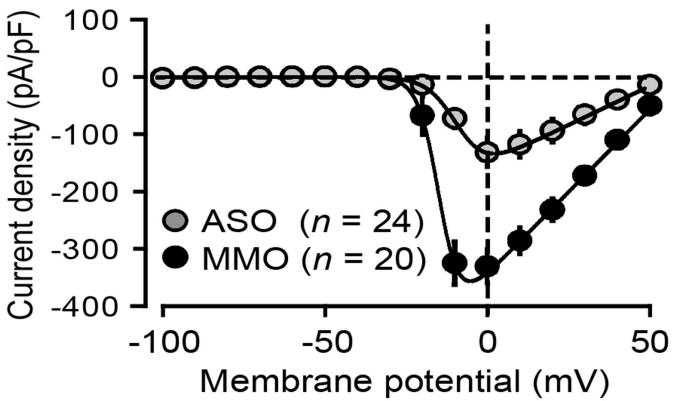

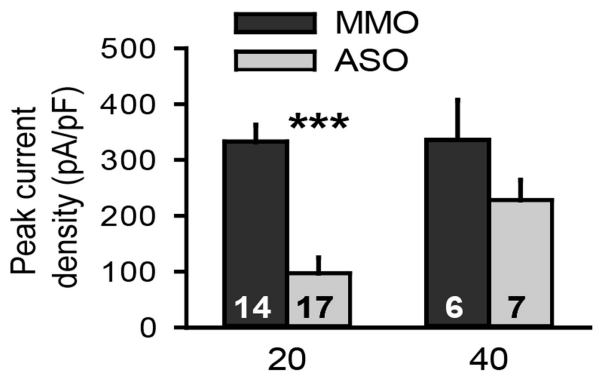

Time after last injection $(h)$

\section{B}

\section{Spontaneous activity (SA) after Nav1.8 knockdown}
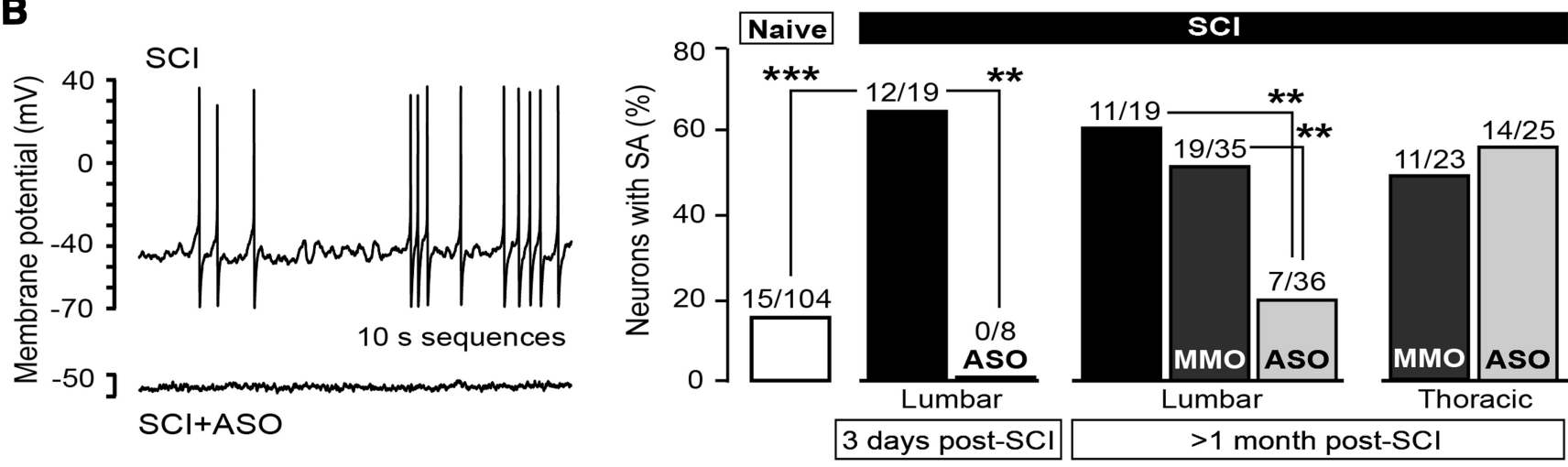

Figure 2. In vivo Nav1.8 antisense treatment reduces TTX-resistant $\mathrm{Na}^{+}$current and SA in small primary afferent neurons tested in vitro after SCI. $\boldsymbol{A}$, Reduction of TTX-resistant current $18-24$ h after Nav1.8 ASO injection. Depolarizing steps evoked smaller currents compared with MM0 treatment (left and middle). Peak TTX-resistant current was significantly reduced $\sim 20 \mathrm{~h}$, but not $\sim 40$ h, after the last ASO injection (right). $\boldsymbol{B}, \mathrm{ASO}$ treatment decreased the incidence of SA (example in left) $3 \mathrm{~d}$ and $1-2$ months after SCI (right). Significant suppression from lumbar Nav1.8 ASO injection occurred in lumbar, but not thoracic (T8, T9, T11, T12), DRG neurons.

A Mechanical sensitivity

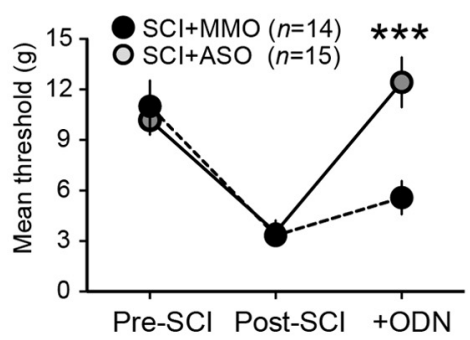

B Heat sensitivity

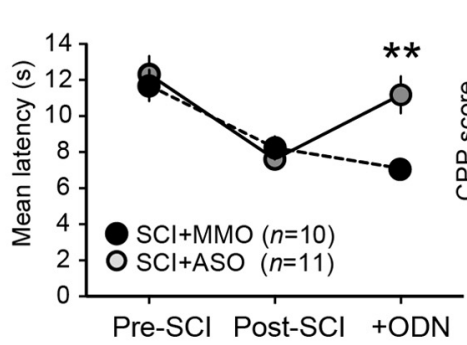

C Conditioned place preference (CPP)
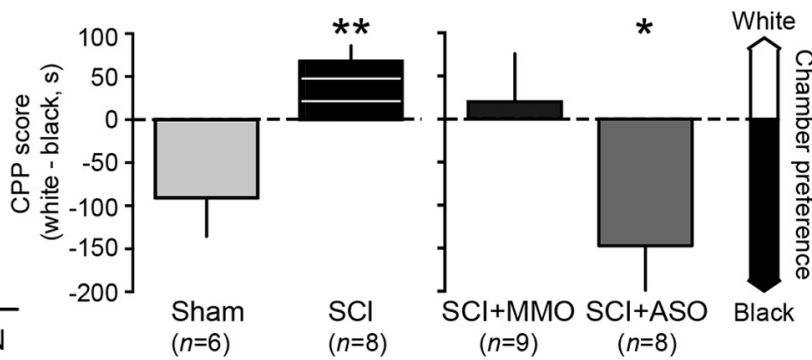

Figure 3. In vivo Nav1.8 ASO treatment reverses behavioral indications of hyperreflexia and pain 1-3 months after SCI. A, Nav1.8 ASO treatment reversed the reduction in mechanical threshold for hindlimb withdrawal. $\boldsymbol{B}$, Nav1.8 ASO treatment reversed the reduction in latency for withdrawal to heat. $\boldsymbol{C}$, Intraperitoneal injections of retigabine supported (PP after SCI (left), which was prevented in SCl animals by Nav1.8 ASO treatment (right). CPP score (left axis) quantifies relative preference (indicated by arrows on right) for the white (retigabine paired) and black (vehicle paired) chambers after conditioning.

DRG neurons and the degree of reflex hypersensitivity (Bedi et al., 2010). Third, an intervention that selectively reduces activity in primary sensory neurons (Nav1.8 knockdown) blocks a CPP measure of ongoing pain that captures its aversive quality (Navratilova et al., 2013). Because retigabine's effects may involve central as well as peripheral mechanisms (Brown and Passmore, 2009), it was important that the drug was only present during conditioning, not testing. Suppression by retigabine of ongoing pain during conditioning rather than long-lasting central actions or intrinsic reward value was indicated by the lack of retigabine-dependent CPP in sham, naive (unpublished observations), or Nav1.8 SCI + ASO animals. The finding of retigabine- dependent CPP after SCI adds to operant evidence for SCIinduced aversive states in rodents (Baastrup et al., 2010; Davoody et al., 2011; Lau et al., 2012; Vierck et al., 2013).

In many nociceptors, Nav1.8 channels are responsible for the upstroke of the action potential (Renganathan et al., 2001), which could explain suppression of SA by knockdown of Nav1.8. Upregulation of Nav1.8 after SCI is likely to contribute to generalized nociceptor hyperexcitability and might contribute to increased SA (Choi and Waxman, 2011), although multiple electrophysiological alterations probably promote nociceptor SA after SCI (Bedi et al., 2010; Wu et al., 2013). Regardless of the complexity of SA mechanisms, the requirement for Nav1.8 sug- 
gests that interventions preferentially targeting nociceptive primary afferent neurons, such as antagonists of Nav1.8 (Jarvis et al., 2007) or TRPV1 (Wu et al., 2013), may relieve some forms of central neuropathic pain.

\section{References}

Akopian AN, Sivilotti L, Wood JN (1996) A tetrodotoxin-resistant voltagegated sodium channel expressed by sensory neurons. Nature 379:257262. CrossRef Medline

Akopian AN, Souslova V, England S, Okuse K, Ogata N, Ure J, Smith A, Kerr BJ, McMahon SB, Boyce S, Hill R, Stanfa LC, Dickenson AH, Wood JN (1999) The tetrodotoxin-resistant sodium channel SNS has a specialized function in pain pathways. Nat Neurosci 2:541-548. CrossRef Medline

Alexander JK, Popovich PG (2009) Neuroinflammation in spinal cord injury: therapeutic targets for neuroprotection and regeneration. Prog Brain Res 175:125-137. CrossRef Medline

Baastrup C, Maersk-Moller CC, Nyengaard JR, Jensen TS, Finnerup NB (2010) Spinal-, brainstem- and cerebrally mediated responses at- and below-level of a spinal cord contusion in rats: evaluation of pain-like behavior. Pain 151:670-679. CrossRef Medline

Baron R, Hans G, Dickenson AH (2013) Peripheral input and its importance for central sensitization. Ann Neurol 74:630-636. CrossRef Medline

Basso DM, Beattie MS, Bresnahan JC (1995) A sensitive and reliable locomotor rating scale for open field testing in rats. J Neurotrauma 12:1-21. CrossRef Medline

Bedi SS, Yang Q, Crook RJ, Du J, Wu Z, Fishman HM, Grill RJ, Carlton SM, Walters ET (2010) Chronic spontaneous activity generated in the somata of primary nociceptors is associated with pain-related behavior after spinal cord injury. J Neurosci 30:14870-14882. CrossRef Medline

Brown DA, Passmore GM (2009) Neural KCNQ (Kv7) channels. Br J Pharmacol 156:1185-1195. CrossRef Medline

Carlton SM, Du J, Tan HY, Nesic O, Hargett GL, Bopp AC, Yamani A, Lin Q, Willis WD, Hulsebosch CE (2009) Peripheral and central sensitization in remote spinal cord regions contribute to central neuropathic pain after spinal cord injury. Pain 147:265-276. CrossRef Medline

Cavanaugh DJ, Chesler AT, Jackson AC, Sigal YM, Yamanaka H, Grant R, O’Donnell D, Nicoll RA, Shah NM, Julius D, Basbaum AI (2011) Trpv1 reporter mice reveal highly restricted brain distribution and functional expression in arteriolar smooth muscle cells. J Neurosci 31:5067-5077. CrossRef Medline

Choi JS, Waxman SG (2011) Physiological interactions between $\mathrm{Na}(\mathrm{v}) 1.7$ and $\mathrm{Na}(\mathrm{v}) 1.8$ sodium channels: a computer simulation study. J Neurophysiol 106:3173-3184. CrossRef Medline

Cummins TR, Dib-Hajj SD, Black JA, Akopian AN, Wood JN, Waxman SG (1999) A novel persistent tetrodotoxin-resistant sodium current in SNSnull and wild-type small primary sensory neurons. J Neurosci 19:RC43. Medline

Davoody L, Quiton RL, Lucas JM, Ji Y, Keller A, Masri R (2011) Conditioned place preference reveals tonic pain in an animal model of central pain. J Pain 12:868-874. CrossRef Medline

Dib-Hajj SD, Ishikawa K, Cummins TR, Waxman SG (1997) Insertion of a SNS-specific tetrapeptide in S3-S4 linker of D4 accelerates recovery from inactivation of skeletal muscle voltage-gated Na channel mu1 in HEK293 cells. FEBS Lett 416:11-14. CrossRef Medline

Finnerup NB (2013) Pain in patients with spinal cord injury. Pain 154:S71S76. CrossRef Medline

Gold MS, Weinreich D, Kim CS, Wang R, Treanor J, Porreca F, Lai J (2003) Redistribution of $\mathrm{Na}(\mathrm{V}) 1.8$ in uninjured axons enables neuropathic pain. J Neurosci 23:158-166. Medline

Hu S, Xiao Y, Zhu L, Li L, Hu CY, Jiang X, Xu GY (2013) Neonatal maternal deprivation sensitizes voltage-gated sodium channel currents in colonspecific dorsal root ganglion neurons in rats. Am J Physiol Gastrointest Liver Physiol 304:G311-G321. CrossRef Medline

Jarvis MF, Honore P, Shieh CC, Chapman M, Joshi S, Zhang XF, Kort M, Carroll W, Marron B, Atkinson R, Thomas J, Liu D, Krambis M, Liu Y, McGaraughty S, Chu K, Roeloffs R, Zhong C, Mikusa JP, Hernandez G, et al. (2007) A-803467, a potent and selective Nav1.8 sodium channel blocker, attenuates neuropathic and inflammatory pain in the rat. Proc Natl Acad Sci U S A 104:8520-8525. CrossRef Medline

Joshi SK, Mikusa JP, Hernandez G, Baker S, Shieh CC, Neelands T, Zhang XF, Niforatos W, Kage K, Han P, Krafte D, Faltynek C, Sullivan JP, Jarvis MF,
Honore P (2006) Involvement of the TTX-resistant sodium channel Nav 1.8 in inflammatory and neuropathic, but not post-operative, pain states. Pain 123:75-82. CrossRef Medline

King T, Vera-Portocarrero L, Gutierrez T, Vanderah TW, Dussor G, Lai J, Fields HL, Porreca F (2009) Unmasking the tonic-aversive state in neuropathic pain. Nat Neurosci 12:1364-1366. CrossRef Medline

Lai J, Gold MS, Kim CS, Bian D, Ossipov MH, Hunter JC, Porreca F (2002) Inhibition of neuropathic pain by decreased expression of the tetrodotoxin-resistant sodium channel, NaV1.8. Pain 95:143-152. CrossRef Medline

Lau D, Harte SE, Morrow TJ, Wang S, Mata M, Fink DJ (2012) Herpes simplex virus vector-mediated expression of interleukin-10 reduces below-level central neuropathic pain after spinal cord injury. Neurorehabil Neural Repair 26:889-897. CrossRef Medline

McKay SM, McLachlan EM (2004) Inflammation of rat dorsal root ganglia below a mid-thoracic spinal transection. Neuroreport 15:1783-1786. CrossRef Medline

Miao XR, Gao XF, Wu JX, Lu ZJ, Huang ZX, Li XQ, He C, Yu WF (2010) Bilateral downregulation of Nav1.8 in dorsal root ganglia of rats with bone cancer pain induced by inoculation with Walker 256 breast tumor cells. BMC Cancer 10:216. CrossRef Medline

Morgan JR, Gebhart GF (2008) Characterization of a model of chronic orofacial hyperalgesia in the rat: contribution of NA(V) 1.8. J Pain 9:522-531. CrossRef Medline

Navratilova E, Xie JY, King T, Porreca F (2013) Evaluation of reward from pain relief. Ann N Y Acad Sci 1282:1-11. CrossRef Medline

Piller N, Decosterd I, Suter MR (2013) Reverse transcription quantitative real-time polymerase chain reaction reference genes in the spared nerve injury model of neuropathic pain: validation and literature search. BMC Res Notes 6:266. CrossRef Medline

Porreca F, Lai J, Bian D, Wegert S, Ossipov MH, Eglen RM, Kassotakis L, Novakovic S, Rabert DK, Sangameswaran L, Hunter JC (1999) A comparison of the potential role of the tetrodotoxin-insensitive sodium channels, PN3/SNS and NaN/SNS2, in rat models of chronic pain. Proc Natl Acad Sci U S A 96:7640-7644. CrossRef Medline

Renganathan M, Cummins TR, Waxman SG (2001) Contribution of $\mathrm{Na}(\mathrm{v}) 1.8$ sodium channels to action potential electrogenesis in DRG neurons. J Neurophysiol 86:629-640. Medline

Roza C, Laird JM, Souslova V, Wood JN, Cervero F (2003) The tetrodotoxin-resistant $\mathrm{Na}+$ channel $\mathrm{Nav} 1.8$ is essential for the expression of spontaneous activity in damaged sensory axons of mice. J Physiol 550: 921-926. CrossRef Medline

Shields SD, Ahn HS, Yang Y, Han C, Seal RP, Wood JN, Waxman SG, DibHajj SD (2012) Nav1.8 expression is not restricted to nociceptors in mouse peripheral nervous system. Pain 153:2017-2030. CrossRef Medline

Vierck CJ, Cannon RL, Acosta-Rua AJ (2013) Evaluation of lateral spinal hemisection as a preclinical model of spinal cord injury pain. Exp Brain Res 228:305-312. CrossRef Medline

Villarreal CF, Sachs D, Cunha FQ, Parada CA, Ferreira SH (2005) The role of $\mathrm{Na}(\mathrm{V}) 1.8$ sodium channel in the maintenance of chronic inflammatory hypernociception. Neurosci Lett 386:72-77. CrossRef Medline

Walters ET (2012) Nociceptors as chronic drivers of pain and hyperreflexia after spinal cord injury: an adaptive-maladaptive hyperfunctional state hypothesis. Front Physiol 3:309. CrossRef Medline

Wu Z, Yang Q, Crook RJ, O’Neil RG, Walters ET (2013) TRPV1 channels make major contributions to behavioral hypersensitivity and spontaneous activity in nociceptors after spinal cord injury. Pain 154:2130-2141. CrossRef Medline

Yang Q, Wu Z, Crook RJ, Du J, Carlton SM, Walters ET (2013) Opening of KCNQ/Kv7 channels blocks both spontaneous activity in small DRG neurons and signs of chronic pain after spinal cord injury. Journal of Pain 14:S54.

Yoshimura N, Seki S, Novakovic SD, Tzoumaka E, Erickson VL, Erickson KA, Chancellor MB, de Groat WC (2001) The involvement of the tetrodotoxin-resistant sodium channel $\mathrm{Na}(\mathrm{v}) 1.8$ (PN3/SNS) in a rat model of visceral pain. J Neurosci 21:8690-8696. Medline

Yu YQ, Zhao F, Guan SM, Chen J (2011) Antisense-mediated knockdown of $\mathrm{Na}(\mathrm{V}) 1.8$, but not $\mathrm{Na}(\mathrm{V}) 1.9$, generates inhibitory effects on complete Freund's adjuvant-induced inflammatory pain in rat. PLoS One 6:e19865. CrossRef Medline 